\title{
CLINICAL AND EPIDEMIOLOGICAL FINDINGS OF HEPATITIS-A OUTBREAK IN DHOKE KANETY, ISLAMBAD
}

\author{
Mumtaz A Khan', Muazam A. R. ${ }^{1}$ Ansari JA 1 , Tayyab R.Rathore ${ }^{1}$, Amir M Baig ${ }^{2}$, Shehla Muzafar ${ }^{2}$ Rana M \\ Safdar ${ }^{1}$, Jawad A Rana ${ }^{2}$.
}

${ }^{1}$ National Institute of Health Islamabad, ${ }^{2}$ Field Epidemiology \& Laboratory Training Program. Corresponding Author: MumtazAli Khan, Medical Officer, National Institute of Health, Islamabad, Email: drmomi74@hotmail.com

\begin{abstract}
Background: Hepatitis-A has an estimated global disease burden of 1.4 million/ year. Poor sanitation leads to children getting infected before the age of 10. A cluster of 10 Hepatitis-A patients was reported from Dhok-Kanety, Islamabad (approx. population 225) and an outbreak investigation was conducted from February 09-15, 2014.

Methods: A case control study was conducted during 9-10 February 2014 in Dhoke Kanety, District Islamabad, Pakistan. A total of 24 cases and 72 Age and gender matched controls were selected from the study area. A case definition for Hepatitis A developed by World Health Organization was used to identify the suspected and confirmed cases. The cases and controls were interviewed and information was collected using a questionnaire including basic epidemiologic information, symptoms, time of onset, medical care, previous history of Jaundice, drinking water sources, consumption of raw vegetables and salad, and sanitation facilities. Samples of blood and water collected for laboratory analysis. Blood samples were tested through 3rd generation ELISA technique and water samples were analyzed through Physiochemical and Microbiological techniques at National Institute of Health Islamabad. Descriptive and inferential methods were used including person chi square test of independence and odd ratios for association. Data was analyzed through Epi-info soft ware and SPSS.

Results: The average age of the respondents remained 8 years (range of 3-13 years). Half of the respondents were female. Overall attack rate was $27 \%$. Among cases, 19 consumed well water (OR 14.4; 95\% Cl 7.5-18.7; $p<0.05$ ); 17 had open-drain toilets (OR 4.5.; 95\% Cl 2.2-6.2; $\mathrm{p}<0.05)$ and 17 had a contact with a case (OR 19; 95\% Cl 7-27; $\mathrm{p}$ $<0.05)$. Moreover, boiling water $(6 / 24$; OR $0.1 ; 95 \% \mathrm{Cl} 0.04-0.3 ; p<0.05)$ and chlorination $(5 / 24$; OR $0.14 ; 95 \% \mathrm{Cl}$ $0.04-0.4 ; p<0.05$ ) showed a protective effect. Results from water samples showed presence of fecal coliforms. Municipal water supply was disrupted due to civil works and a well was used as the source of water.

Conclusion: Contaminated well water was identified as the source of infection. Health education was imparted on hygiene/sanitation.
\end{abstract}

Key words: Hepatitis A, outbreak, Islamabad, risk factors

Introduction:

Hepatitis A virus (HAV), usually self-limiting disease, highly transmissible and one of the most frequent causes of food-borne infections, occurs worldwide, both sporadically and in the form of epidemics. Hepatitis-A has an estimated global disease burden of 1.4 million/ year. Poor sanitation leads to children getting infected before the age of 10 . Acute viral Hepatitis $A$ is a common infection among children in Pakistan and accounts for $50-60 \%$ of all cases of acute viral hepatitis in children. Almost $96 \%$ of the population is exposed to HAV by the age of 5 years and $98-100 \%$ at adulthood (18). Hepatitis A virus (HAV) first isolated in 1979, is primarily transmitted by the fecal-oral route. a non-enveloped RNA virus that is classified as a picornavirus. Humans are the only host and can be stable in the environment for months depending on conditions. The virus is relatively stable at low $\mathrm{pH}$ levels and moderate temperatures and can be inactivated by high temperature $\left(185^{\circ} \mathrm{F}\left[85^{\circ} \mathrm{C}\right]\right.$ or higher), formalin, and chlorine (1).

After ingestion, reaches the liver, replicates and after 10-12 days, virus is present in blood and is excreted via the biliary system into the feces. The virus is can be found in stools during the 1-2 weeks before and for 1-3 weeks after onset of illness. Children and infants may excrete virus longer than adults (1).

The average incubation period is 28 days (range: $15-50$ days). 1 In children younger than 6 years of age, most $(70 \%)$ infections are asymptomatic. In older children and adults, infection is usually symptomatic, with jaundice occurring in more than $70 \%$ of patients. Approximately $33 \%$ of people with reported cases of hepatitis A are hospitalized; hospitalization rates increase with increasing age. 3 Overall mortality among reported cases of hepatitis-A is approximately $0.3 \%$ $0.6 \%$; however, among adults older than 50 years of age, mortality is $1.8 \% .1$ The illness presentation varies widely: there may be flu-like symptoms, fever, malaise, anorexia, nausea, abdominal discomfort, dark urine and 
jaundice. Clinical illness usually resolves within 2 months among about $65 \%$ of cases and within 6 months for nearly all cases. There is no specific treatment for hepatitis A virus infection. Disease is usually self-limiting and treatment and management of HAV infection are supportive; HAV infection does not result in chronic infection or chronic liver disease. However, HAV infection can complicate chronic liver disease among persons infected with hepatitis $C$ virus; thus, susceptible persons should be vaccinated.(2). Rapid identification and prompt reporting of hepatitis A cases are important to take timely preventive measures and to enlist contacts who can effectively be vaccinated.(19)

\section{Methodology:}

A case control study was conducted during 9-10 February 2014 in Dhoke Kanety, District Islamabad, Pakistan. A total of 24 cases were enrolled with 72 Age and gender matched controls from the study area. A case definition for Hepatitis-A developed based on World Health Organization standard case definition, to identify suspected and confirmed cases. The persons reported with previous history of hepatitis-A or received vaccination against hepatitis-A within last 3 months were excluded. The cases and controls were interviewed and information was collected using a questionnaire including basic epidemiologic information, symptoms, time of onset, medical care, previous history of Jaundice, drinking water sources, consumption of raw vegetables and salad, and sanitation facilities.

Blood and water samples were collected for laboratory analysis. Serum from both case and controls were tested using 3rd generation ELISA technique for specific anti-hepatitis-A and Hepatitis-E IgM antibodies. Risk factors were assessed through the questionnaire. Blood samples were also tested for Viral Hepatitis B \& C. Water samples were analyzed in Environmental Laboratory of the National Institute of Health $(\mathrm{NIH})$ for chemical as well as microbiological parameters.

Descriptive and inferential methods were used including pearson-chi square test of independence and odds ratios for association. Data was analyzed through Epiinfo software and SPSS.

\section{Results:}

\section{Blood tests:}

A total of 10 blood samples were analyzed as representative samples for confirmation of the outbreak at NIH for Hepatitis A \& E and were found positive for Hepatitis-A IgM while negative for HEV, Hepatitis B \& C.

\section{Environmental investigation:}

Four water samples from different sources including well were taken and analyzed in Environmental Laboratory of the National Institute of Health $(\mathrm{NIH})$ where the all samples were declared unfit for drinking with heavy growth of indicator organisms (feacal coliforms). While checking the water sources, it was found that the main water supply pipelines were disrupted due to new township construction work beside the village and the only source of drinking water was an old large well in the village. The well was not well covered and possibility of contamination with rain water and sewerage water was there. Around the well, there were animal's sheds and sewerage water having animal excreta. The water was supplied through temporary pipelines to most of the houses in the village. The water was being used without any treatment and the well water was never chlorinated in near past. In most of the houses, washrooms were without proper drainage system and the sewerage was directly drained to nearby open fields. Most children affected had contacts with other ill children and none of the ill individuals in this outbreak had received hepatitisA vaccine as vaccines are difficult to afford in the region.

\section{Epidemiological findings:}

Twenty Four cases were identified with the average age of 8 years (range of 3-13 years). Overall attack rate was $27 \%$. Among the study subjects $58 \%$ were female. The findings from this outbreak investigation suggest that a $4 y$ rs old female child, developed symptoms in the last week of December, 2013, being the index case, transmitted HAV to other children in the family and resulted in subsequent transmission of infection among other children in the village.

\section{Clinical findings:}

Clinical symptoms reported were Jaundice 100\%(24), Anorexia $100 \%(24)$, Lethargy $100 \%(24)$, Nausea $85 \%$ (20), Vomiting $67 \%(16)$, abdominal pain $58 \%(14)$, Fever 37\% (9) and Loose stools 42\%(10).

Significant Risk factors: An old uncovered well in the village used for drinking water source was significantly related to Hepatitis-A and $40 \%$ of the respondents exposed to well water got infected $(p<0.05$. The persons consumed well have 14.4 times more chances to get infected as compared with those not consumed well water (OR 14.4 95\% Cl 7.5-18.7). 52\% respondents got infection out of the total respondents who used water without water treatment options (Boiling, Filter, Chlorination) and remained significantly associated with Hepatitis $A(p<0.00)$. Boiling of the water remained protective for the Hepatitis-A infection (OR $0.195 \% \mathrm{Cl}$ 0.04-0.3). Similarly chlorination also remained protective OR $0.14 ; 95 \% \mathrm{Cl} 0.04-0.4 ; \mathrm{p}<0.05) .48 \%$ of positive cases have washroom with open drain and remained significant risk factor $(p=0.03)$. The respondents having open drain washroom have 4.5 times more chances to get infected with Hepatitis-A(OR $4.595 \% \mathrm{Cl} 2.2-6.2$ ). Among positive cases, 70\% (17/24) have contact with jaundice patient and contact history remained significantly associated with Hepatitis-A. The respondents having contact with a jaundice patients have 19 times more chances to get infected with Hepatitis-A(OR 21 with 95\% Cl 6-77). (Table 1) 
Table1: Potential Risk Factors associated with Hepatitis-A ( $n=96)$

\begin{tabular}{|c|c|c|c|c|}
\hline Risk Factors & Positive & Negative & $\begin{array}{c}\text { P- } \\
\text { value }\end{array}$ & $\begin{array}{c}\text { OR } \\
(95 \% \mathrm{Cl})\end{array}$ \\
\hline $\begin{array}{c}\text { Drinking water Source } \\
\text { Well } \\
\text { Pipeline }\end{array}$ & $\begin{array}{l}24(39 \%) \\
0(0 \%)\end{array}$ & $\begin{array}{l}37(61 \%) \\
30(100 \%)\end{array}$ & 0.000 & $\begin{array}{l}14.4 \\
(7.5- \\
18.7\end{array}$ \\
\hline $\begin{array}{c}\text { Do you treat water } \\
\text { Yes } \\
\text { No }\end{array}$ & $\begin{array}{l}2(4 \%) \\
22(52 \%)\end{array}$ & $\begin{array}{l}47(96 \%) \\
20(48 \%)\end{array}$ & .0000 & $\begin{array}{c}0.1 \\
(0.04- \\
0.3)\end{array}$ \\
\hline $\begin{array}{l}\text { Type of washroom used } \\
\text { Outdoor Open } \\
\text { Pit Type } \\
\text { Indoor closed } \\
\text { drain } \\
\text { Indoor with open } \\
\text { drain }\end{array}$ & $\begin{array}{l}0 \\
4(17 \%) \\
8(20 \%) \\
12(44 \%)\end{array}$ & $\begin{array}{l}1(100 \%) \\
19(83 \%) \\
32(80 \%) \\
15(56 \%)\end{array}$ & 0.03 & $\begin{array}{c}4.5 \\
(2.2- \\
6.2)\end{array}$ \\
\hline $\begin{array}{l}\text { Contact with Hepatitis- } \\
\text { A patient } \\
\text { Yes } \\
\text { No }\end{array}$ & $\begin{array}{l}17(71 \%) \\
7(10 \%)\end{array}$ & $\begin{array}{l}7(29 \%) \\
60(90 \%)\end{array}$ & 0.02 & $\begin{array}{c}19(7- \\
27)\end{array}$ \\
\hline
\end{tabular}

\section{Discussion:}

This report describes an outbreak of hepatitis-A among children in a small village of Islamabad Capital Territory. A sharp increase the patients presented with acute Jaundice was noted by a General Practitioner of the area. The same was reported to District Health Department for exploring the cause and taking preventive measures. Twenty Four cases were identified including 14 active cases. Most of the affected individuals were children below 15 years with average age 8 years (3-13 years). In developing countries HAV cases occurs sporadically and children acquire the infection in early life making them immune to another attack ( 7$)$.

Overall attack rate was $27 \%$. Among the cases females were more frequent $58 \%$. The present outbreak was waterborne as indicated by this study. Similar studies on investigation of acute viral hepatitis have been published supporting our findings (4-6).

All patients were treated on outdoor basis. This outbreak started in 1st week of January (week 1st) to 8th March 2014 (week 11) with peak from week 6 to 10 and then started declining. The disease is mostly self limiting and patients recover without any serious complication (1). No secondary peak was observed, similar finding were reported by varied studies $(\underline{6,9,10,15)}$.

Twenty four cases and 64 age-sex matched controls were enrolled in the study. Control subjects were similar to case patients with respect to age, race, and sex. Almost all case patients reported consumption of old well water located in the village. Other potential sources of infection identified were using raw vegetables, lack of proper sewerage system and sanitation, hand washing especially after attending washroom. Acute viral hepatitis (A\&E) is responsible for the hepatitis outbreak as well as sporadic cases of hepatitis in developing countries (7).

Clinical symptoms reported were Jaundice $100 \%(24)$, Anorexia 100\%(24), Lethargy $100 \%(24)$, Nausea $85 \%$ (20), Vomiting 67\% (16), abdominal pain $58 \%(14)$, Fever $37 \%$ (9) and Loose stools $42 \%(10)$. A total of 67 age and gender matched controls were taken for identification of the potential risk factors related to this outbreak. A well in the village used for drinking water source was significantly related to Hepatitis-A 40\% (24/61 $p=0.000)$ as compared to pipeline water supply $0 \%(0 / 30)$, Water treatment options(boiling, filter, chlorination) remained protective for Hepatitis-A $(p=0.000)$, $48 \%$ of positive cases have washroom with open drain and remained significant risk factor $(p=0.03)$. Among positive cases $70 \%(17 / 24)$ have contact with jaundice patient (OR 21 with $95 \% \mathrm{Cl} 6-77$ ). The study findings are supported by other similar studies in India and other developing countries $(13,14,17)$.

Among cases, 19 consumed well water (OR 14.4; $95 \%$ Cl 7.5-18.7; p <0.05); 17 had open-drain toilets (OR 4.5.; 95\% Cl 2.2-6.2; $\mathrm{p}<0.05$ ) and 17 had a contact with a case (OR 19; 95\% Cl 7-27; p $<0.05)$. Moreover, boiling water $(6 / 24$; OR 0.1 ; $95 \% \mathrm{Cl} 0.04-0.3 ; \mathrm{p}<0.05)$ and chlorination (5/24; OR $0.14 ; 95 \% \mathrm{Cl} 0.04-0.4 ; \mathrm{p}<0.05)$ showed a protective effect. A clear association was observed between contaminated water supply and occurrence of cases of hepatitis. Chlorination and boiling of water was also found protective.

Drinking water was obtained from a nearby old well which was never treated and was located 
next to a vegetable field that was often fertilized by faeces, a possible source of contamination. It was found that the main water supply pipelines were disrupted due to new township construction work beside the village. The well was not well covered and possibility of contamination with rain water and sewerage water was there. Around the well, there were animal's sheds and sewerage water having animal excreta. The water was being used without any treatment and the well water was never chlorinated in near past. A similar observation was made by Banerjee et al. in their study (8). The termination of the outbreak following the chlorination of the water sources and adopting good hygienic practices further supported our hypothesis.

In most of the houses, washrooms were without proper drainage system and the sewerage was directly drained to nearby open fields which could possibly contaminated vegetables fields. Hand washing practices of the children in the village especially after attending washrooms were not found appropriate. Most children affected had contacts with other ill children. So poor sanitation and hygienic practices also played a role in the spread of the disease to other healthy nonimmune children. These findings are supported by other similar studies $(11,12)$.

\section{Conclusion:}

Based on the above observations, it was concluded that, the present outbreak was due to fecal contamination of well water which was the only drinking water sources and were uncovered, exposed to heavy contamination. Poor hygienic conditions and using raw vegetables are among the other potential risks. Awareness about safe drinking water, treatment options and sanitation were negligible.

\section{References:}

1. Wasley A, Feinstone SM, and Bell BP. Hepatitis A Virus in: Mandell, Douglas, and Bennett's Principles and Practice of Infectious Diseases. 7th ed., Copyright 2009 Churchill Livingstone Elsevier, Philadelphia, PA.

2. Klevens RM, Kruszon-Moran D, Wasley A, Gallagher K, McQuillan GM, Kuhnert W, Teshale EH, Drobeniuc J, Bell BP. Seroprevalence of Hepatitis A Antibodies in the United States: Results from the national Health and Nutrition Examination Survey. Public Health Rep. 2011;126(4)
3. A Multistate, Foodborne Outbreak of Hepatitis AYvan J.F. Hutin, M.D., Vitali Pool, M.D., Elaine H. Cramer, M.D., Omana V. Nainan, Ph.D., Jo Weth, M.A., Ian T. Williams, Ph.D., Susan T. Goldstein, M.D., Kathleen F. Gensheimer, M.D., Beth P. Bell, M.D., Craig N. Shapiro, M.D., Miriam J. Alter, Ph.D., and Harold S. Margolis, M.D. for the National Hepatitis A Investigation Team N Engl J Med 1999; 340:595-602February 25, 1999DOI: 10.1056/NEJM199902253400802

4. Eurosurveillance, Volume 19, Issue 37, 18 September 2014 Surveillance and outbreak reports; Hepatitis A outbreak in Italy, 2013: a matched case-control study C MontañoRemacha 1,2, L Ricotta1,3, V Alfonsi1, A Bella1, M E Tosti1, A R Ciccaglione1, R Bruni1, S Taffon1, M Equestre1, M N Losio4, V Carraro5, S Franchini5, B Natter6, M Augschiller6, A Foppa6, C Gualanduzzi7, E Massimiliani7, A C Finarelli7, B M Borrini7, T Gallo8, V Cozza2,9, M Chironna10, R Prato9, C Rizzo1, Central Task Force on Hepatitis 11

5. Indian J Community Med. 2014 Apr;39(2):94-7. doi: 10.4103/0970-

0218.132725. Epidemiological investigation of the jaundice outbreak in lalkuan, nainital district, uttarakhand. Awsathi S1, Rawat V2, Rawat CM1, Semwal V1, Bartwal SJ1. Indian J Community Med. 2010 Apr;35(2):294-7. doi: 10.4103/09700218.66864.

6. Epidemic investigation of the jaundice outbreak in girdharnagar, ahmedabad, gujarat, India, 2008. Chauhan NT1, Prajapati P, Trivedi AV, Bhagyalaxmi A.

7. Sarguna P, Rao A, Sudha Ramana KN. Outbreak of acute viral hepatitis due to hepatitis virus in Hyderabad. Indian J Med Microbiol. 2007;25:378-82.

8. Banerji A, Sahni AK, Rajiva, Nagendra A, Saiprasad GS. Outbreak of viral hepatitis in a regimental training. Med $\mathrm{J}$ Armed Forces India. 2005; 61:326-9.

9. Western Pac Surveill Response J. 2009 2011 Oct;32(10):1014-7. doi: 10.5365/WPSAR.2012.3.4.014. Print 2012 Oct.

10. An outbreak of hepatitis A associated with a contaminated well in a middle school, Guangxi, China. Ye-Qing X1, Fu-Qing C, 
Jia-Tong Z, Guo-Ming Z, Jin-Fa D, Qu-Yun $D$, Hui-Min L. Fiore AE, Wasley A, Bell BP. Prevention of hepatitis $A$ through active or passive immunization. MMWR. Morbidity and Mortality Weekly Report. 2006;55(RR07):1-23.

11. Zheng $\mathrm{H}$, et al. Epidemiological analysis on hepatitis A in China during 2004-2006. Chinese Journal of Vaccines and Immunization. 2007;13:336-41.

12. Li LI, et al. Analysis and countermeasure for current situation of hepatitis A, B in China. Disease Surveillance. 2009;24:307-12.

13. Hai-tian SUI, et al. Epidemic characteristics on hepatitis A in China during 1990-2006. Chinese Journal of Vaccines and Immunization. 2007;13:466-9.

14. Committee on Infectious Diseases Hepatitis A vaccine recommendations. Pediatric. 2007;12:189-99.

15. Western Pac Surveill Response J. 2012 Oct-Dec; 3(4): 44-47. Published online 2012 Dec 20. doi: 10.5365/WPSAR.2012.3.4.014 PMCID: PMC3729089

16. An outbreak of hepatitis $A$ associated with a contaminated well in a middle school,
Guangxi, China Xu Ye-qing,a,b Cui Fuqing,c Zhuo Jia-tong,d Zhang Guo-ming,c Du Jin-fa,d Den Qu-yun,c and Luo Hui-minc

17. J Korean Med Sci. 2014 Feb; 29(2): 248253. Published online 2014 Jan 28. doi: 10.3346/jkms.2014.29.2.248 PMCID:

PMC3924005 Clinical Characteristics and Outcomes of Acute Hepatitis A in Korea: A Nationwide Multicenter Study

So Young Kwon,1 Sang Hoon Park,2 Jong Eun Yeon,3 Sook Hyang Jeong,4 Oh Sang Kwon,5 Jin Woo Lee,6 Hong Soo Kim,7 Yeon Seok Seo,8 Young Seok Kim, 9 Joo Hyun Sohn,10 Hyung Joon Yim,11 Jong Young Choi,12 Myung Seok Lee,2 Young Oh Kweon,13 Jae Youn Cheong,14 Haak Cheoul Kim, 15 Heon Ju Lee,16 Soon Koo Baik,17 Hyonggin An,18 and Kwan Soo Byun

18. Shah U, Habib Z, Kleinman RE. Liver failure attributable to hepatitis-A virus infection in a developing country. Pediatrics 2000; 105: 436-8.

19. VPD Surveillance Manual, 5th Edition, 2011 Hepatitis A: Chapter 3-1 